Dear members,

\title{
Season's Greetings
}

I am sure, all of you would agree that, we are going through one of the most crucial and critical time of mankind, due to COVID-19.

This pandemic has posed significant challenges for dentistry and the medical profession, as a whole.

With the heightened and tightened measures in our SOPs, I trust we will be able to continue to practice dentistry safely.

So sincerely requesting all my fellow members and colleagues to "Stay healthy and stay safe" and always to follow all the necessary preventions and precautions in your daily professional, as well as personal life.

In this time of uncertainty, due to the fluidity of the outbreak of COVID-19, we are preparing for the upcoming APEX 2021 and PG Midterm Convention, but only with your understanding and whole hearted support. Will update on the development of these events, in the due course.

On behalf of the Executive Committee members, I wish all of you, a "Happy and Prosperous New year, 2021."

Together we will get through this!

Yours in, CAESOK

Romel Joseph MDS

President, CAESOK 